\title{
А.С. Созинов
}

Казанский медицинский университет, Казань, Российская Федерация

\section{Педиатры $64^{1}$}

\section{Автор, ответственный за переписку:}

Созинов Алексей Станиславович, доктор медицинских наук, ректор Казанского медицинского университета

Адрес: 420012, Казань, ул. Бутлерова, д. 49, тел.: +7 (843) 236-06-52, e-mail: rector@kgmu.kcn.ru

В основу статьи положено выступление ректора Казанского государственного медицинского университета на VIII конференции "Педиатрия и детская хирургия в Приволжском федеральном округе" 20 сентября 2011 г., посвященной 70-летию выдающихся российских педиатров - академика А.А. Баранова, профессоров В.Ю. Альбицкого, А.В. Кузнецовой, С.В. Мальцева, О.И. Пикузы, выпускников педиатрического факультета КГМУ 1964 г. Представлены сведения о научном творчестве и вкладе юбиляров в педиатрическую науку, в дело охраны здоровья детского населения Татарстана и России.

Ключевые слова: педиатрия, Казанская педиатрическая школа

Для цитирования: Созинов А.С. Педиатры 64. Педиатрическая фармакология. 2021;18(1):80-83. doi: 10.15690/pf.v18i1.2233

Одно из самых понятных, логичных и в то же время самых загадочных явлений - профессиональное, творческое взаимодействие людей в самых разных вариантах. Наиболее заметны творческие союзы. Без этого мы не прочитали бы удивительные книги Ильфа и Петрова, не смеялись бы над карикатурами Кукрыниксов, не рассказывали бы нашим детям сказки братьев Гримм. Если речь зашла о родственниках, то стоит вспомнить как вариант благотворного человеческого синергизма - династии.

Например, в истории Казанской медицинской школы - династия Миславских. Основатель А.А. Миславский, уральский хирург-легенда, выпускник медфака Казанского университета, которому Совет медфака присвоил почетное звание доктора медицины (hanore hause) без защиты. Его сын Николай Александрович Миславский - классик русской физиологии, член-корреспондент Академии наук СССР, заведующий кафедрой физиологии медфака Казанского университета. Его внук Александр Николаевич Миславский - знаменитый отечественный гистолог, создатель советской школы нейрогистологов, заслуженный деятель науки России, заведующий кафедрой гистологии Казанского государственного медицинского института (КГМИ). Его правнук
Андрей Дмитриевич Адо - один из основоположников отечественной аллергологии как науки и клинического раздела медицины, академик АМН СССР, заведующий кафедрой патофизиологии КГМИ (1938-1952) и Российского государственного медицинского университета (РГМУ) им. Н.И. Пирогова (1952-1995).

Не менее волнующей, может быть, даже более эмоциональной формой поддержки в бизнесе и творчестве является союз одноклассников от классического Царскосельского лицея до современного сайта "Одноклассники", пользующегося необычайной популярностью в интернете.

И еще одна общность - однокурсники. Согласитесь, в истории каждой школы, каждого вуза есть классы, курсы, выпуски, которыми по праву гордятся не только их альма матер, но и все профессиональное сообщество. Так, не только в историю Казанского государственного медицинского университета (КГМУ), Казанской медицинской школы и медицины Татарстана, но в историю отечественной медицины и здравоохранения войдет, уже вошел выпуск КГМИ 1964 года.

1964 год - полвека тому назад, начало космической эры, конец послевоенного периода, эпохи Н.С. Хрущева и оттепели. Среди выпускников КГМИ 1964 года во второй половине XX века многие стали талантливыми орга-

\section{Alexander S. Sozinov}

Kazan State Medical University, Kazan, Russian Federation

\section{Pediatricians 64}

Article is based on performance of the Rector of the Kazan State Medical University at the VIII Conference "Pediatrics and Pediatric Surgery in the Volga Federal District" September 20, 2011, devoted to the 70th anniversary of the famous Russian pediatricians academician A.A. Baranov, professors V.Yu. Albitsky, A.V. Kuznetsova, S.V. Maltsev, O.I. Pikuza, who graduated Department of Pediatrics KSMA in 1964. Presents data on scientific creativity and contribution of anniversaries in pediatric science, to the protection of the health of the child population of Tatarstan and Russia.

Keywords: pediatrics, Kazan pediatric school

For citation: Sozinov Alexander S. Pediatricians 64. Pediatricheskaya farmakologiya — Pediatric pharmacology. 2021;18(1):80-83. doi: 10.15690/pf.v18i1.2232

1 Данная статья впервые опубликована: Практическая медицина. - 2012. - Т. 7. - № 12. - С. 174-177. Публикуется с разрешения правообладателя. 
низаторами здравоохранения, известными, блестящими врачами-практиками. Нет возможности всех назвать, перечислить, да и задача нынешней встречи более академичная. Назову имена только тех из этого выпуска, кто стал профессором, заведующим кафедрой. Итак, по алфавиту:

1) Альбицкий Валерий Юрьевич - заведующий отделом социальной педиатрии Научного центра здоровья детей (НЦЗД) $\mathrm{PAMH}^{2}$, профессор кафедры поликлинической и социальной педиатрии РГМУ, заслуженный деятель науки РФ, лауреат премии Правительства РФ, почетный профессор КГМУ;

2) Баранов Александр Александрович - директор НЦЗД РАМН, вице-президент РАМН, академик РАН и РАМН, заведующий кафедрой педиатрии и детской ревматологии педиатрического факультета Первого Московского медицинского университета им. И.М. Сеченова, главный внештатный специалистпедиатр Минздрава РФ, председатель Исполкома Союза педиатров России, лауреат премии Правительства РФ, лауреат премий имени Н.Ф. Филатова и А.А. Богомольца РАМН, почетный профессор КГМУ;

3) Кузнецова Алевтина Васильевна - заведующая кафедрой педиатрии и неонатологии Казанской государственной медицинской академии (КГМА), заслуженный врач РТ;

4) Мальцев Станислав Викторович - заведующий кафедрой педиатрии КГМА, заслуженный деятель науки РФ и РТ, член-корреспондент АН РТ, лауреат Российской премии им. А.А. Киселя и Республиканской премии им. А.Г. Терегулова;

5) Маянский Андрей Николаевич - заведующий кафедрой микробиологии Нижегородской государственной медицинской академии, член-корреспондент РАЕН, лауреат премии им. А.А. Богомольца РАМН;

6) Медведев Вячеслав Николаевич (1940-1995) заведующий кафедрой хирургии № 2 Казанского государственного медицинского университета, заслуженный врач РТ и РФ;

7) Пикуза Ольга Ивановна - заведующая кафедрой факультетской педиатрии (1985-2009) Казанского государственного медицинского университета, заслуженный деятель науки РТ, лауреат Государственной премии РТ;

8) Салихов Ильдар Газимджанович - заведующий кафедрой госпитальной терапии Казанского государственного медицинского университета, членкорреспондент АН РТ, лауреат Государственной премии РТ, заслуженный деятель науки РТ, заслуженный врач РФ и РТ;

9) Семенов Валерий Семенович - заведующий кафедрой лучевой диагностики Чувашского государственного университета;

10) Уразгильдеев Загид Исмаилович - заведующий отделеним Центрального института травматологии и ортопедии Минздравсоцразвития РФ.

Среди названных десяти профессоров, четверо выпускники лечебного факультета, причем все из одной группы, из 4-й, а шестеро - педиатрического факультета, и опять же четверо (Альбицкий, Баранов, Кузнецова, Уразгильдеев) из одной группы, из 12-й. Что это - закономерность или случайность, талантливые объединяются или воспроизводят друг друга? Демокрит сказал, что "случайными называют события, причины которых мы не знаем". ("Случай - это псевдоним Бога, когда он не хочет ставить свой автограф", Анатоль Франс.)

2 Ныне - «НМИЦ здоровья детей» Минздрава России.
Но сегодня мы чествуем педиатров, отмечаем 80-летие выдающихся ученых Татарстана и России профессоров В.Ю. Альбицкого, А.А. Баранова, А.В. Кузнецовой, С.В. Мальцева. О.И. Пикузы. Каждый из них внес весомый вклад в развитие педиатрической науки, в подготовку кадров детских врачей.

Кратко скажу о наиболее выдающихся заслугах наших юбиляров.

Начну с самого главного, и не только потому что он действительно по штату Минздравсоцразвития РФ главный специалист педиатр, а потому что его знает вся наша страна как главного детского доктора. Думаю, что после великого русского педиатра Георгия Нестеровича Сперанского такую должность в России никто не занимал и долго не займет. Думаю также, что уже сегодня Александр Александрович Баранов занимает достойное место в плеяде самых выдающихся выпускников Казанского государственного медицинского университета, представителей Казанской медицинской школы.

Крайне трудно выделить главную заслугу А.А. Баранова, настолько они взаимосвязаны, пронизаны между собой. Позволю привлечь внимание аудитории лишь к наиболее важным, с моей точки зрения, достижениям многогранной деятельности юбиляра, которые достаточно ярко иллюстрируют масштаб личности академика.

ПЕРВОЕ. А.А. Баранов входит в ту плеяду руководителей отечественного здравоохранения - выпускников КГМУ, которые определяли его развитие в непростые, переломные моменты истории нашего Отечества. Он стоит в одном ряду с нашими выпускниками Н.А. Семашко, 3.П. Соловьевым, С.В. Курашевым. Занимая должность заместителя, а затем первого заместителя министра здравоохранения СССР в 1987-1991 годах, А.А. Баранов разработал стратегию борьбы с младенческой смертностью. Реализация указанной стратегии даже в условиях начавшегося социально-экономического кризиса конца 80-х годов сформировала тренд снижения смертности детей на первом году жизни, а в тяжелейшие "лихие" 90-е среди показателей состояния здоровья населения России уровень младенческой смертности был единственным, не свалившимся в тартарары. И как только страна чуть оправилась от кризиса, он стал неуклонно снижаться. И то, что в 2010 году показатель младенческой смертности составил 7,5\% (а был в 1987 г. в пределах $21 \%$ ) и стал сопоставим с таковыми в европейских странах, во многом заслуга главного педиатра страны.

ВТОРОЕ. По инициативе А.А. Баранова, благодаря его неистощимой энергии был создан уникальный, не имеющий аналогов в мире Научный центр здоровья детей РАМН, объединивший под одной крышей профилактическую, клиническую и реабилитационную педиатрию. В Центре используют все современные профилактические, диагностические, лечебные и реабилитационные технологии. Среди его пациентов дети не только из большинства регионов нашей страны, но также и ближнего и дальнего зарубежья.

TPETЬЕ. Для большинства, а то и для всех педиатров страны А.А. Баранов - бессменный председатель Союза педиатров России. Создав его в 1994 г. как правопреемника Общества детских врачей СССР, он превратил Союз в мощное авторитетное общественное объединение. Регулярно два раза в год Союз проводит свои февральские Конгрессы в Москве и сентябрьские в регионах, тем самым доводя до педиатров страны все последние достижения медицинской науки и практики. Союз педи- 
атров стал пользоваться международным авторитетом, свидетельство тому - проведение 4-го Европейского Конгресса в Москве, избрание академика А.А. Баранова вице-президентом Европейской педиатрической ассоциации, членом Исполкома Международной педиатрической ассоциации.

ЧЕTВEРТОЕ. В начале XXI века чиновники из Минздрава России решили внедрять европейскую модель семейного врача, передав ему функции педиатра первичного звена здравоохранения. А.А. Баранов организует и возглавляет мощную общественную кампанию против слепого подражания западному образцу, доказывая, что отечественная система охраны здоровья детей, когда детского врача готовят на специальных факультетах и он работает в первичном звене, доказала свою высокую эффективность, стала для многих, в т.ч. и европейских стран, примером для подражания. И бой был выигран! Педиатров не отлучили от семейной общей практики.

ПЯТОЕ. А.А. Баранов - основоположник известной педиатрической школы, под его руководством выросли более 80 докторов и кандидатов медицинских наук. Его ученики возглавляют кафедры педиатрии в Нижнем Новгороде, Москве, Казани, Саранске, Ставрополе и других городах России. Между прочим, первая докторская диссертация, выполненная при консультации А.А. Баранова, принадлежит Валерию Юрьевичу Альбицкому.

Далее представляю наших юбиляров по алфавиту. Но даже если б фамилия Валерия Юрьевича начиналась на букву "я", все равно после рассказа об академике Баранове я был бы обязан, вынужден назвать фамилию Альбицкого. И не в силу каких-то его научных и общественных заслуг, их не меньше у других юбиляров. И дело здесь в замечательном обстоятельстве. Баранов и Альбицкий являют нам пример человеческой с большой буквы Дружбы! Начиная со студенческих лет, более полувека они идут вместе по жизни, и, как сказал Валерий Юрьевич, "не только написать об этом, но и подумать без удивления, восторга, а то и страха трудно". А фундаментом, скрепившим их дружбу, стало Дело по имени "Охрана здоровья российских детей". Я бы их дружбу образно обозначил так: “Баранов и Альбицкий - как две башни одного Кремля". Только вот не могу решить какого: Казанского, Нижегородского или Московского?..

Не умаляя научных заслуг В.Ю. Альбицкого в области педиатрии, прежде всего социальной педиатрии, одним из лидеров которой в России он, безусловно, является, я остановлюсь не на читинском, не на нижегородском и даже не на московском периодах его жизни и творчества, а только на казанском. Его без преувеличения можно назвать летописцем Казанской медицинской школы. По его инициативе и при непосредственном участии были написаны два фундаментальных труда - «История Казанского медицинского университета" и "Биографический словарь заведующих кафедрами и профессоров КГМУ". Последний послужил примером для ряда медицинских вузов страны, где были созданы аналогичные словари. По инициативе В.Ю. Альбицкого было положено начало Актовому торжеству. Не только традиционная Актовая речь, но целый комплекс праздничных мероприятий с 1996 года реализуется 14 мая в день рождения КГМУ. Без преувеличения скажу: этот день стал праздничным событием для медицинской общественности Республики Татарстан.

В историю КГМУ В.Ю. Альбицкий вошел и как основатель первой в стране кафедры, объединившей под одной крышей преподавание биомедицинской этики и медицинского права. Присоединением к ним курса истории медицины в университете был создан мощный бастион гуманитарной составляющей высшего медицинского образования. Согласитесь, в сегодняшних реалиях знание этики и права, воспитание историей, этикой и правом - актуальное, неотложное дело.

Наконец, В.Ю. Альбицкий оставил и другой отменный казанский след. Из 67 подготовленных им докторов и кандидатов наук 7 профессоров работают в Казани, четверо из них заведуют кафедрами. В.Ю. Альбицкому единственному в мире присвоено почетное звание "Заслуженный Садыковед" - четверо его учеников носят фамилию Садыков.

Профессор Алевтина Васильевна Кузнецова прежде всего запомнилась сегодняшним юбилярам как принципиальный, инициативный комсорг 12-й группы. Свидетели утверждают, что с ней было ох как трудно договориться, чтоб она отметила как присутствующих на лекциях отсутствующих по прогулочным, весенним причинам одногруппников. А.В. Кузнецова прошла типичный академический путь. Занятия в студенческом кружке и учеба в аспирантуре на кафедре госпитальной педиатрии КГМУ у профессора Абруй Хусаиновны Хамидуллиной, а затем в течение 20 лет - работа ассистентом этой кафедры. В 1989 году после защиты докторской диссертации она приглашена возглавить кафедру педиатрии № 2 Казанского ГИДУВа. И вот оно - и веление времени, и связь времен! В те годы А.А. Баранов как раз начинает разрабатывать и реализовывать концепцию борьбы с младенческой смертностью, одно из приоритетных направлений которой развитие перинатологии и неонатологии, организация в стране перинатальных центров.

Этот призыв выдающегося одногруппника был услышан и блестяще реализован А.В. Кузнецовой Она вошла в историю здравоохранения Татарстана и Казанской медицинской школы как один из ярких основоположников неонатологии в Республике. По ее инициативе кафедра педиатрии № 2 преобразуется в кафедру педиатрии и перинатологии (некоторое время спустя - неонатологии) КГМА, которую она возглавляла в течение 20 лет. В начале 90-х годов она подготовила команду неонатологов в ведущих клиниках России и США, Австрии, Германии, Голландии. Эта команда совместно с профессорами Балтиморского университета провела несколько учебных циклов по неонатологии для врачей Татарстана и соседних регионов. А.В. Кузнецова стояла у истоков организации в РТ неоперинатологии как специализированной службы, начиная от закладки в 1994 году первого камня в фундамент Республиканского перинатального центра. И если сегодня Татарстан имеет один из самых низких показателей младенческой смертности, то в этом есть немалая заслуга профессора А.В. Кузнецовой.

Не будет юбилейным преувеличением, если я скажу, что в настоящее время лидером Казанской школы педиатров является заслуженный деятель науки Российской Федерации и Республики Татарстан профессор Станислав Викторович Мальцев. Основания для такого заявления следующие. Во-первых, он в течение целых 35 лет заведует кафедрой педиатрии в КГМА, во-вторых, более четверти века возглавляет Республиканское отделение Союза педиатров России. Им подготовлено более 40 докторов и кандидатов наук, многие из них являются заведующими кафедрами, профессорами и доцентами в медицинских вузах Татарстана, Чувашии, Удмуртии. 
С.В. Мальцеву выпала историческая миссия соединить мединститутскую и гидувскую школы казанских педиатров. С одной стороны, он всегда позиционировал себя учеником профессора Клавдии Андреевны Святкиной (между прочим, все наши сегодняшние юбиляры вспоминают ее добрыми словами, называют своим любимым деканом). С другой стороны, С.В. Мальцев занял кафедру, которую основал в ГИДУВе выдающийся отечественный педиатр Ефим Моисеевич Лепский. С.В. Мальцев продолжил дело своих выдающихся предшественников в области изучения витаминов. Впервые в СССР совместно со своими учениками он изучил обеспеченность витамином D беременных, новорожденных и детей разных возрастов, что позволило коренным образом пересмотреть вопросы клинического применения витамина D c профилактической и лечебной целью. Он также провел серию исследований по выяснению основных патогенетических механизмов различных форм рахита у детей, разработал критерии диагностики и лечения его резистентных форм. Есть все основания заявить, что труды Лепского, Святкиной и Мальцева внесли весомый вклад в мировую педиатрию в области детской витаминологии, профилактики и лечения одной из самых распространенных патологий раннего детства - рахита.

$\mathrm{He}$ менее впечатляющи научные достижения С.В. Мальцева в области экологической педиатрии. Он установил нормативы содержания целого спектра микроэлементов (цинк, стронций, алюминий, кремний, свинец и др.) в различных биологических жидкостях у здоровых детей, а затем изучил патогенетическое и клиническое значение изменения их содержания при заболеваниях почек, различных формах рахита, патологии органов пищеварения. На основании этих исследований была разработана система медико-экологической реабилитации детей.

Завершаю свое выступление словом об одной из самых обаятельных женщин КГМУ - профессоре Ольге Ивановне Пикузе. Она блестящий ученый, талантливый педагог и из врачей, которых в народе называют "чудо-врач". Не одно поколение казанцев, когда у них возникали серьезные проблемы со здоровьем детей, искали у нее помощи и получали эту помощь.

О.И. Пикуза после окончания с красным дипломом института, отработав 3 года участковым педиатром, поступила в ординатуру на кафедру детских болезней лечебного факультета КГМИ, на которой затем работала ассистентом. В 1985 году О.И. Пикуза возглавила кафедру пропедевтики детских болезней, а после ее объединения с кафедрой факультетской педиатрии - кафедру педиатрии № 1 КГМУ и заведовала этой кафедрой четверть века.

Как ученый профессор О.И. Пикуза получила широкую известность в области изучения систем опсонофагоцитоза и колонизационной резистентности при инфекционно-воспалительных заболеваниях у детей, проживающих в экологически неблагополучных районах. Началом этих исследований стала ее докторская диссертация, защищенная в 1983 году. И опять не могу не сказать о примечательном с точки зрения истории КГМУ факте. Одним из консультантов докторской диссертации О.И. Пикузы был ее сокурсник, выдающийся специалист в области иммунологии и микробиологии Андрей Николаевич Маянский. Названные исследования профессора О.И. Пикузы, как и работы профессора С.В. Мальцева, внесли весомый вклад в развитие отечественной экологической педиатрии, продолжили давнюю традицию Казанской медицинской школы - творческое содружество клиницистов и гигиенистов.

О.И. Пикуза известна и как талантливый педагог. Ее лекции пользуются популярностью и у студентов, и у врачей-педиатров, ибо они эмоциональны по форме, фундаментальны по содержанию. Она подготовила более 20 докторов и кандидатов наук. Особая страница в педагогической и общественной деятельности О.И. Пикузы ее деканство. 12 лет она возглавляла педиатрический факультет. Как когда-то наши юбиляры называли своего любимого декана, профессора К.А. Святкину, второй матерью, так и студенты-педиатры 90-х годов прошлого века считали второй матерью профессора О.И. Пикузу. Вспомните, какие это были тяжелейшие годы в истории постсоветской России. Душевная щедрость и стремление помочь в любой студенческой беде - такой запомнилась декан педфака того времени.

Прошло 10 лет со времени моего выступления, положенного в основу настоящей статьи. Слава Богу, наши герои продолжают плодотворно служить благородному делу охраны здоровья детей. А это значит, несомненно будет реализован лозунг, выдвинутый академиком А.А. Барановым: "Сохраним здоровье детей - сохраним Россию»!

\section{ОТ РЕДАКЦИИ}

Одному из персонажей настоящей статьи профессору А.В. Кузнецовой уже исполнилось, а другим в 2021 году грянет 80 лет. Редакция журнала «Педиатрическая фармакология" посчитала, что лучшим способом рассказать педиатрической общественности о юбилярах, известных российских педиатрах, - это перепечатать статью ректора Казанского медицинского университета профессора А.С. Созинова. Ибо в ней, на наш взгляд, ярко, емко, убедительно представлен материал о весомом вкладе в педиатрическую науку и практику выпускников КГМУ, получивших диплом детского врача 56 лет назад. Считаем также важным с чувством светлой зависти сообщить, что герои публикации продолжают активно трудиться.

Альбицкий Валерий Юрьевич - главный научный сотрудник НИИ педиатрии и охраны здоровья детей ЦКБ РАН.

Баранов Александр Александрович - главный внештатный специалист педиатр Минздрава РФ.

Кузнецова Алевтина Васильевна - консультант ряда детских ЛПУ.

Мальцев Станислав Викторович - профессор кафедры педиатрии имени академика Г.Н. Сперанского Российской медицинской академии непрерывного профессионального образования.

Пикуза Ольга Ивановна - профессор кафедры пропедевтики детских болезней и факультетской педиатрии Казанского государственного медицинского университета.

Отдаем также дань светлой памяти ушедшим из жизни профессорам Салихову Ильдару Газимджановичу (1941-2011), Маянскому Андрею Николаевичу (1940-2015) и Уразгильдееву Загиду Исмаиловичу (1941-2019). 